\title{
Galacto-oligosaccharides increase calcium absorption and gut bifidobacteria in young girls: a double-blind cross-over trial
}

\author{
Corrie M. Whisner ${ }^{1}$, Berdine R. Martin ${ }^{1}$, Margriet H. C. Schoterman ${ }^{2}$, Cindy H. Nakatsu ${ }^{3}$, \\ Linda D. McCabe ${ }^{4}$, George P. McCabe ${ }^{4}$, Meryl E. Wastney ${ }^{5}$, Ellen G. H. M. van den Heuvel ${ }^{2,6}$ \\ and Connie M. Weaver ${ }^{1 *}$ \\ ${ }^{1}$ Department of Nutrition Science, Purdue University, Stone Hall, $700 \mathrm{~W}$. State Street, West Lafayette, IN 47907, USA \\ ${ }^{2}$ FrieslandCampina, Stationsplein 4, 3818 LE, Amersfoort, The Netherlands \\ ${ }^{3}$ Department of Agronomy, Purdue University, Stone Hall, 700 W. State Street, West Lafayette, IN 47907, USA \\ ${ }^{4}$ Department of Statistics, Purdue University, Stone Hall, $700 \mathrm{~W}$. State Street, West Lafayette, IN 47907, USA \\ ${ }^{5}$ Metabolic Modeling Services, Stone Hall, 700 W. State Street, West Lafayette, IN 47907, USA \\ ${ }^{6}$ Department of Epidemiology and Biostatistics, EMGO Institute for Health and Care Research, VU University Medical Center, \\ Amsterdam, The Netherlands
}

(Submitted 30 August 2012 - Final revision received 9 January 2013 - Accepted 9 January 2013 - First published online 14 March 2013)

\begin{abstract}
Adolescence is a time for rapid growth that represents an opportunity to influence peak bone mass. Prebiotic agents, such as galactooligosaccharides (GOS), increase Ca absorption in animal models and postmenopausal women. The objectives of the present study were to investigate the dose-response relationship of GOS supplementation on Ca absorption during growth and to assess changes in colonic microbiota to better understand the mechanism by which GOS is acting. A total of thirty-one healthy adolescent girls aged 10-13 years consumed smoothie drinks twice daily with $0,2.5$ or $5 \mathrm{~g}$ GOS for three 3 -week periods in a random order. Fractional Ca absorption was determined from urinary Ca excretion over $48 \mathrm{~h}$ at the end of each 3-week period using a dual stable isotope method. Faecal microbiota and bifidobacteria were assessed by PCR-denaturing gradient gel electrophoresis and quantitative PCR. Fractional Ca absorption after the $48 \mathrm{~h}$ treatment with control, 5 and $10 \mathrm{~g} \mathrm{GOS/d} \mathrm{was} \mathrm{0.393} \mathrm{(sD} \mathrm{0.092),} \mathrm{0.444} \mathrm{(sD} \mathrm{0.086)} \mathrm{and} \mathrm{0.419} \mathrm{(sD} \mathrm{0.099),} \mathrm{respectively.}$ Significant improvements in Ca absorption were seen with both low and high doses of GOS compared with the control $(P<0 \cdot 02)$, but it was not a dose-response relationship. The increase in absorption was greatest in the urine collected after $24 \mathrm{~h}$, which is consistent with lower gut absorption. Faecal bifidobacteria increased (control 10.89 (sD 13.86), $5 \mathrm{~g}$ GOS 22.80 (sD 15.74) and 10 g GOS 11.54 (sD 14.20)) with the GOS treatment $(P<0 \cdot 03)$. The results suggest that daily consumption of $5 \mathrm{~g}$ GOS increases Ca absorption, which may be mediated by the gut microbiota, specifically bifidobacteria.
\end{abstract}

Key words: Prebiotic: Calcium absorption: Bifidobacteria: Galacto-oligosaccharides

Prebiotics have become more prevalent in foodstuffs with the growing interest in functional foods and their role in health and disease prevention. Non-digestible oligosaccharides meet the FAO and the WHO definition of a prebiotic ${ }^{(1)}$ as they are thought to influence indigenous bacteria and have beneficial physiological effects, including a role in bone health. Adolescence is an important time period for maximising peak bone mass to prevent the development of osteoporosis later in life. The high bone mineral accrual velocity that occurs during adolescence presents a unique opportunity to influence peak bone mass through modifiable lifestyle factors, such as diet and exercise. Current $\mathrm{Ca}$ consumption is well under the recommended $1300 \mathrm{mg} / \mathrm{d}$ for adolescents in the $\mathrm{USA}^{(2)}$. An alternative approach to improving Ca nutrition is to increase Ca bioavailability. A growing body of literature suggests that non-digestible oligosaccharides, including galacto-oligosaccharides (GOS), have beneficial effects on $\mathrm{Ca}$ metabolism and bone health through increasing $\mathrm{Ca}$ absorption $^{(3)}$.

GOS are non-digestible carbohydrates consisting of chains of galactose with a glucose end piece, varying in chain length from two to eight monomers. They are produced by means of enzymatic conversion of lactose, and are being used on a large scale in infant nutrition, dairy products and

Abbreviations: BMC, bone mineral content; DGGE, denaturing gradient gel electrophoresis; GOS, galacto-oligosaccharides; rRNA, ribosomal RNA. 
beverages. Other terms being used for GOS are transgalactooligosaccharides or $\beta$-GOS. GOS are believed to resist digestion, allowing it to be fermented in the large intestine, in particular by bifidobacteria to produce SCFA and decrease $\mathrm{pH}$. In healthy adults, consumption of $10 \mathrm{~g} / \mathrm{d}$ of GOS for $21 \mathrm{~d}$ resulted in significant increases in faecal bifidobacteria content $^{(4)}$, while in vitro work has shown increased production of SCFA in the presence of $\mathrm{GOS}^{(5)}$. Changes in the intestinal surface area have also been associated with prebiotic consumption resulting in caecal hypertrophy ${ }^{(6,7)}$. In rats fed GOS diets, increased crypt depth and cell density in the proximal and distal colon were observed ${ }^{(8)}$.

Fermentation may directly increase $\mathrm{Ca}$ absorption through hydrogen ion exchange ${ }^{(9)}$ or indirectly through hypertrophy of the intestinal mucosa to increase the surface area for greater mineral diffusion. Several studies have shown a positive effect of GOS on Ca absorption $^{(8,10)}$ and bone density ${ }^{(11,12)}$ in rats. Recently, we have shown that GOS increased Ca absorption and bone mineral density through decreased $\mathrm{pH}$, increased bifidobacteria composition and increases in caecal wall and content weight ${ }^{(13)}$. Work in human subjects has been scarce with varying results. Supplementation with a gradually increasing dose from 5 to $10 \mathrm{~g} / \mathrm{d}$ of GOS twice per $\mathrm{d}$ for $9 \mathrm{~d}$ increased Ca absorption by $16 \%$ in postmenopausal women ${ }^{(14)}$. Conversely, a similar study in young men has found no effect of $15 \mathrm{~g} / \mathrm{d}$ of GOS for $21 \mathrm{~d}$ on Ca absorption ${ }^{(15)}$; however, this study did not allow enough gut transit time of the $\mathrm{Ca}$ tracer to include colonic absorption. No studies of GOS on Ca absorption have been reported in children and adolescents. Ca absorption fraction is up-regulated during pubertal growth, yet other prebiotics including fructo-oligosaccharides enhance $\mathrm{Ca}$ absorption efficiency during this life stage ${ }^{(16)}$.

The aims of the present study were to assess the effect of GOS given in a smoothie drink on Ca absorption in healthy premenarcheal girls, and to evaluate the timing of $\mathrm{Ca}$ absorption and changes in gut microbiota to speculate on the mechanism of action. We hypothesised that GOS would increase colonic $\mathrm{Ca}$ absorption in a dose-response manner associated with changes in the total number of microbiota and bifidobacteria.

\section{Experimental methods}

\section{Subjects}

Through local advertising, thirty-one premenarcheal girls between the ages of 10 and 13 years were enrolled in the present study. All subjects were healthy and were not taking any medications that could alter bone and Ca metabolism or gut microbial profiles. Additional inclusion criteria included consuming greater than $700 \mathrm{mg} \mathrm{Ca} / \mathrm{d}$ as measured with a validated dietary assessment tool. Scores from this FFQ were previously associated with total hip bone mineral content (BMC) and femoral neck BMC after adjustment for covariates ${ }^{(17)}$. Dietary assessment tool scores measured at baseline were also predictive of BMC after 12 months $^{(17)}$. Exclusion criteria included disordered Ca or bone homeostasis, BMI greater than the 90th percentile for age, smoking or drug use, autoimmune or inflammatory gastrointestinal diseases, broken bone within last 6 months, disease affecting kidney function, dislike of smoothie drinks and regular consumption of foods containing prebiotics or probiotics. Subjects were asked to discontinue the use of vitamin and mineral supplements before consuming the smoothies and while participating in the study. They were also asked to avoid consuming products that contained probiotics and/or prebiotics over the course of the intervention. The present study was conducted according to the guidelines laid down in the Declaration of Helsinki, and all procedures involving human subjects were approved by the Institutional Review Board of Purdue University. Written informed consent was obtained from all subjects. The study was registered at ClinicalTrials.gov (ID: NCT01263847).

\section{Study design}

The present study was a randomised, double-blind cross-over trial with three treatments. Treatments consisted of smoothie drinks supplemented with $0,2.5$ or $5 \mathrm{~g}$ GOS (Vivinal ${ }^{\circledR}$ GOS Syrup containing 59\% GOS (percentage of DM); see Table 1 for the typical composition of Vivinal ${ }^{\circledR}$ GOS; FrieslandCampina Domo) that were consumed twice per $\mathrm{d}$, amounting to total GOS intakes of 0,5 and $10 \mathrm{~g} / \mathrm{d}$.

Smoothie drinks (International Food Network Inc.) (see Table 2 for composition of smoothies) were consumed at breakfast and dinner for 3 weeks, followed by a clinical visit at Purdue which included a controlled diet, Ca absorption test, collection of all excreta and a breath test to identify methane producers, who lack or have a lower number of sulphate-reducing bacteria compared with non-methanogenic individuals ${ }^{(18)}$. Each phase was separated by a 2 -week period to washout any effect of the intervention on gut colonisation. A baseline blood sample was taken at the start of the study to assess markers of health including $\mathrm{Hb}$, haematocrit, C-reactive protein, serum $\mathrm{Zn}$, Fe-soluble transferrin receptor and serum ferritin levels. Anthropometric measurements, bone strength measures by peripheral quantitative computer tomography and physical fitness assessments were also performed during one of the three treatment periods in order to check whether the children had normal bone characteristics based on a sexspecific reference. Clinical visits occurred Friday evening through Sunday night, during which time subjects were accommodated in either a Purdue University residence hall or a local hotel.

\section{Diets}

During the clinical visit, subjects were provided with controlled diets containing approximately $700 \mathrm{mg}$ Ca plus the

Table 1. Typical composition of Vivinal ${ }^{\circledR}$ GOS Syrup

\begin{tabular}{lc}
\hline Formula components & $\mathrm{DM}(\%)$ \\
\hline Galacto-oligosaccharides & 59 \\
Lactose & 21 \\
Glucose & 19 \\
Galactose & 1 \\
DM & 75 \\
\hline
\end{tabular}


Table 2. Composition of smoothie drinks (\%)

\begin{tabular}{lccc}
\hline Ingredients & 0g GOS & $2.5 \mathrm{~g} \mathrm{GOS}$ & $5.0 \mathrm{~g} \mathrm{GOS}$ \\
\hline Whole milk & 59 & 59 & 59 \\
Water & 2.2 & 3.0 & 3.4 \\
Pectin slurry & 13.1 & 13.4 & 13.7 \\
Sucrose & 3.0 & 3.0 & 3.0 \\
Maize syrup & 18.5 & 11.5 & 5.0 \\
GOS syrup (Vivinal ${ }^{\circledR}$ GOS) $\dagger$ & 0.0 & 5.9 & 11.7 \\
Ca & 2.9 & 2.9 & 2.9 \\
Citric acid & 0.9 & 0.9 & 0.9 \\
Strawberry flavour and red colour & 0.4 & 0.4 & 0.4 \\
Total & 100 & 100 & 100 \\
\hline
\end{tabular}

GOS, galacto-oligosaccharides.

${ }^{*}$ Pectin slurry in each smoothie contained $2.6,3$ and $3.2 \%$ sucrose and $3.45,3.35$ and $3.30 \%$ pectin in $0,2.5$ and $5 \mathrm{~g}$ GOS smoothies, respectively.

†Confirmed by analyses with high-performance anion exchange chromatography with pulsed amperometric detection ${ }^{(55)}$.

two smoothies with $300 \mathrm{mg} \mathrm{Ca}$ each (total $\mathrm{Ca}$ in the diet approximately $1300 \mathrm{mg} / \mathrm{d}$ ). The diets were also controlled for fibre content, providing $15 \mathrm{~g}$ dietary fibre/d (with the exception of the prebiotics). Energy needs were calculated at baseline and were kept equal during the three clinical visits. Calculations were based on estimated resting and moderate activity energy expenditures using the Harris-Benedict equation $^{(19)}$. During one washout period between the treatments, subjects were asked to complete a $6 \mathrm{~d}$ diet record to calculate habitual macro- and micronutrient intakes.

\section{Bone health assessment}

Baseline bone strength parameters were assessed on each subject using a series of peripheral quantitative computer tomography (XCT-2000; Stratec Medizintechnik GmbH) scans of the tibia and radius. In total, three sites were scanned on the tibia (4, 38 and 66\%) in addition to the 4 and 20\% sites on the radius. Non-dominant arms and legs were measured unless the subject had experienced a fracture in that limb (one participant had experienced a fracture in her nondominant arm). Analyses of these scans were used to measure cortical and trabecular bone parameters (total area, bone mineral density, BMC, periosteal and endosteal circumferences). Normalised scores were calculated based on bone geometric parameters at the distal radius measured in 629 Caucasian males and females between the ages of 5 and 25 years using lambda, mu, sigma techniques ${ }^{(20)}$.

\section{Compliance}

A total of forty-two smoothie drinks (two smoothies per $\mathrm{d}$ for 3 weeks) were provided to the subjects during each of the three study phases, and subjects were asked to return unconsumed drinks at the start of each clinical visit. Compliance of smoothie consumption was measured with compliance calendars and confirmed by counting the number of unopened smoothie bottles returned at each clinical visit. To complete the calendars, subjects were asked to place a sticker on a calendar for each smoothie they consumed. Collection of urine and faecal samples was monitored at all times throughout the clinical visit by research personnel. Staff accompanied participants to the restroom to assure that samples were collected and labelled appropriately. The counsellor:participant ratio was 1:3.

\section{Fractional calcium absorption}

Following an overnight fast, participants provided a rising urine collection, followed by a fasting collection, on Saturday morning. After these initial urine collections, a stable Ca isotope, ${ }^{44} \mathrm{Ca}(15 \mathrm{mg})$, was given orally with a standardised breakfast meal that provided a total of $300 \mathrm{mg} \mathrm{Ca} .{ }^{44} \mathrm{CaCl}_{2}$ was added to the smoothies for each treatment and allowed to equilibrate overnight before consumption. A second stable isotope, ${ }^{43} \mathrm{Ca}(3.5 \mathrm{mg})$ as ${ }^{43} \mathrm{CaCl}_{2}$, was given intravenously $1 \mathrm{~h}$ after the oral isotope. All urine samples were collected over the $48 \mathrm{~h}$ following isotope administration.

Urine samples were combined to form four $12 \mathrm{~h}$ urine aliquots $(0-12,12-24,24-36$ and 36-48h). Urine samples were analysed for ${ }^{44} \mathrm{Ca}$ and ${ }^{43} \mathrm{Ca}$ enrichment by measuring isotope ratios $\left({ }^{44} \mathrm{Ca}:{ }^{42} \mathrm{Ca}\right.$ and $\left.{ }^{43} \mathrm{Ca}:{ }^{42} \mathrm{Ca}\right)$ via inductively coupled plasma MS (inductively coupled plasma-MS, Finnegan Element2; Thermo Scientific) and total $\mathrm{Ca}$ using atomic absorption spectrometry (AAS, AAnalyst 300; Perkin-Elmer) as described previously ${ }^{(21)}$. Ca absorption was calculated using enrichment values to calculate the $\Delta$ excess for ${ }^{44} \mathrm{Ca}$ and ${ }^{43} \mathrm{Ca}$ as a ratio of ${ }^{44} \mathrm{Ca}:{ }^{43} \mathrm{Ca}$ after accounting for natural abundance and doses given. The equation for fractional $\mathrm{Ca}$ absorption for each $12 \mathrm{~h}$ urine aliquot is shown below.

Fractional $\mathrm{Ca}$ absorption $=$

$\left(\left[\left(\frac{{ }^{44} \mathrm{Ca} /{ }^{42} \mathrm{Ca} \Delta \text { excess }}{{ }^{43} \mathrm{Ca} /{ }^{42} \mathrm{Ca} \Delta \text { excess }}\right) \times\left(\frac{0.02083}{0.00135}\right)\right] \times\left[\frac{\text { intravenous dose }}{\text { oral dose }}\right]\right)$.

Kinetic modelling was used to calculate total Ca absorption over the $48 \mathrm{~h}$ treatment period for subjects where all data time points were collected ( $n$ 15, 15 and 16 for 0,5 and $10 \mathrm{~g}$ GOS, respectively). Tracer ratios were converted to the percentage of the dose given, and the tracer in the urine as well as total $\mathrm{Ca}$ in the urine were fitted by a three-compartment model using the WINSAAM program and average parameter values for teen girls ${ }^{(22)}$. Parameters for absorption, excretion and exchange between the compartments were allowed to adjust for each subject so that the model fitted data for each subject.

\section{Methane production}

Only $30-50 \%$ of Western populations produce methane $e^{(23-25)}$. Methane producers have little to no sulphate-reducing bacteria. It was found that these bacteria have a greater metabolic diversity and capacity when compared with methanogenic bacteria, leading to differences in the turnover of fatty acids in the colon ${ }^{(18)}$. We hypothesised that those children who are identified as methane producers may show a higher GOS-induced enhancement of Ca absorption, possibly due to higher SCFA metabolism within the colon. During each clinical visit, subjects were asked to 
exhale into a Quin Tron ${ }^{\mathrm{TM}}$ sample bag (QuinTron Instrument Company) at least $2 \mathrm{~h}$ after consuming a meal. This test was performed during each clinical visit to assure that the results were accurate, as participants sometimes had difficulties breathing into the bags correctly. Breath samples were then analysed for methane content using a Quin Tron ${ }^{\text {тм }}$ Breath Analyzer (QuinTron Instrument Company). The threshold to identify methane production was $>1$ parts per million and participants were identified as methane producers when methane was detected in breath samples during two or more of the three clinical visits.

\section{Weekly self-reported gastrointestinal symptoms}

During each 3-week GOS intervention, subjects were asked to complete a weekly symptom survey over the phone. Data collected from these surveys included free-response answers and rankings on a scale of $0-5(0=$ absent or no symptom; $5=$ severe occurrence of symptom) for the following symptoms associated with dietary fibre consumption: abdominal pain, bloating, flatulence, diarrhoea, bowel movement frequency and bowel movement consistency.

\section{DNA extraction}

Community DNA was extracted from all faecal samples collected from the subjects during their clinical visit to Purdue at the end of each of the three different GOS treatment tests. Subjects who did not defecate during any of their clinical visits were excluded from this part of the study. In total, faecal samples were collected from twenty-three subjects for DNA extraction. Subjects also collected faecal samples at home (labelled N) before beginning their first treatment. Subjects stored the baseline samples in their freezers until research personnel were notified to pick up and transport the samples to the clinical facility where they were stored in a freezer until processed. Extractions were done using the FastDNA Spin Kit for Soil (MP Biomedicals) adapted for human faecal samples as described previously ${ }^{(26)}$. DNA quality and quantity was assessed using a NanoDrop 1000 spectrophotometer and NanoDrop 3000 fluorospectrometer (Thermo Scientific), respectively.

\section{PCR-denaturing gradient gel electrophoresis}

DNA was used to compare the bacterial communities between subjects by means of $16 \mathrm{~S}$ ribosomal RNA (rRNA) gene PCRdenaturing gradient gel electrophoresis (DGGE), as described in detail previously ${ }^{(13)}$. The $16 \mathrm{~S}$ rRNA gene was amplified by bacterial primers PRBA338F with a GC clamp and PRUN518R ${ }^{(27,28)}$. Agarose gel electrophoresis was used to determine the quality and quantity of PCR products before loading in equivalent quantities in DGGE gels. DGGE (DCode $^{\mathrm{TM}}$ Universal Mutation Detection System; Bio-Rad Laboratories) was performed using $8 \%(\mathrm{w} / \mathrm{v})$ polyacrylamide gels (40\% acrylamide-bis solution, $37 \cdot 5: 1$ ) in $1 \times$ Tris-acetate-EDTA (TAE) buffer with denaturing gradients $(30-50,35-55$ and 45-65\%). Then, three different gradients were used for bacterial community analysis of each sample to optimise band separation to facilitate profile comparisons. All gels included DGGE band migration markers, made from rRNA gene PCR products from individual microbes, to aid in between-gel comparisons. Electrophoresis was initiated at $15 \mathrm{~V}$ for $10 \mathrm{~min}$ and then increased to $200 \mathrm{~V}$ for $5 \mathrm{~h}$. Electrophoresis buffer $(1 \times \mathrm{TAE})$ was maintained at $60^{\circ} \mathrm{C}$ throughout. Gels were stained using SYBR Green I (Cambrex Bio Science), visualised on a UV transilluminator and photographed (UVP BioImaging system; UVP LLC).

\section{Quantitative PCR}

Quantitative PCR was performed using bifidobacteria and bacteria-specific primer sets using a My iQ thermal cycler (Bio-Rad), as described previously ${ }^{(13)}$. Bacterial 16S rRNA gene copy number assessment was performed as described for PCR-DGGE previously with the exception that the GC clamp was excluded from the primer. For bifidobacteria quantification, the primers Bif164F and Bif662 $\mathrm{R}^{(29)}$ were used and annealing was performed at $62^{\circ} \mathrm{C}$, otherwise all conditions were the same as those used for bacteria. Quantitative PCR of each sample was performed in triplicate using the iQ SYBR Green Supermix (Bio-Rad) and 1 ng of template DNA. Positive controls and standard curves for quantification were made from the 16S rRNA gene of Bifidobacterium bifidum cloned into the pGEM-T easy vector (Promega). Standard curves were generated from 10-fold serial dilutions of plasmid DNA. Gene copy numbers were calculated based on total DNA and the percentage of bifidobacteria gene copies in total bacteria.

\section{Statistical analysis}

Statistical analysis was performed using SAS version 9.2 (SAS Institute). To understand the GOS effects on $\mathrm{Ca}$ absorption over time, a general linear model based on the following parameters was used: sequence, participant identifier (ID) nested within sequence, treatment, time and phase. ID nested within sequence was treated as a random variable with ID representing the subjects unique identifier and sequence, the order in which treatments were received. Variables were assessed for potential interactions including time $\times$ treatment and sequence $\times$ treatment interactions. The time $\times$ treatment interaction term in our general linear model was not significant; therefore, conclusions made about treatment differences apply equally to all time periods. Similarly, the interaction between sequence and treatment was also not significant. Group mean differences were determined using least significant difference post hoc comparisons when a variable was significant in the model. The sample size of twenty-three was calculated with an $\alpha$ error of 0.05 and $80 \%$ power to detect a difference in Ca absorption of $5.9 \%$, assuming a standard deviation of 2.9 (SD 9.6) \% ${ }^{(30)}$

To explore the effects of usual $\mathrm{Ca}$ absorption on the response to GOS, Pearson's correlations were used to evaluate correlations between the change in fractional $\mathrm{Ca}$ absorption on 5 or $10 \mathrm{~g} / \mathrm{d}$ of GOS from control and fractional Ca absorption during the control period. Correlations were observed 
when all data were combined together and individually by urine collection time point.

Digital gel images were analysed and PCR-DGGE fingerprint profiles compared using BioNumerics software (version 5.01; Applied Maths). Gels were scored for the presence or absence of DNA bands and all scores from different gradients were combined using the composite dataset function in BioNumerics (Applied Maths) to make a complete profile. Only bands with intensities of $3 \%$ or more were scored as present. DNA banding patterns were compared using Dice similarity indices to identify major contributors to the variation in fingerprints. Quantitative PCR results for bifidobacteria were compared independent of fractional absorption to look for treatment effects. This separate analysis was needed because faecal samples could not be collected in $12 \mathrm{~h}$ time intervals like urine. A general linear model including sequence, ID nested within sequence, treatment and phase was used for this analysis.

Data were removed from analyses in the event of antibiotic use, fractional $\mathrm{Ca}$ absorption resulting in values $<0$ or $>1 \cdot 0$ for specific $12 \mathrm{~h}$ urine samples and non-compliant sample collection. In the event of antibiotic use, subject data were excluded for the phase during which antibiotics were prescribed as well as the following phase to account for any residual effects on faecal bacteria. Statistical significance was set at $P<0 \cdot 05$.

\section{Results}

A total of thirty-one healthy girls participated in the present study (Fig. 1). Of these, six subjects withdrew from the study (four were lost before treatment randomisation and two dropped out after the second treatment phase). Physical and clinical health characteristics of these participants were within normal ranges (Table 3).

\section{Habitual dietary intakes}

Diet records showed that participants habitually consumed approximately $1010 \mathrm{mg} / \mathrm{d} \mathrm{Ca}$ and 13.8 (SD 7.4) g/d dietary fibre (Table 4). Habitual Ca intakes fell below the RDA of $1300 \mathrm{mg} / \mathrm{d}$, but were higher than intakes reported from National Health and Nutrition Examination Survey (NHANES) data (988 6 $(\mathrm{sD} 47 \cdot 1) \mathrm{mg} / \mathrm{d}$ ) for girls $9-13$ years of age ${ }^{(2)}$.

\section{Fracture history and peripheral quantitative computer tomography}

Of the study subjects, nine reported a fracture history during screening, having incurred one or more fractures $>6$ months before the study. Table 3 summarises bone density results of the distal radius, measured by peripheral quantitative computer tomography. The mean radius total density and trabecular density, for which there are reference data, were within the normal range based on sex-specific reference centile curves for age and height. The ranges in $z$-scores for total density and trabecular density of the radius were $-2 \cdot 2$ to $2 \cdot 5$ and $-0 \cdot 2$ to $3 \cdot 7$, respectively.

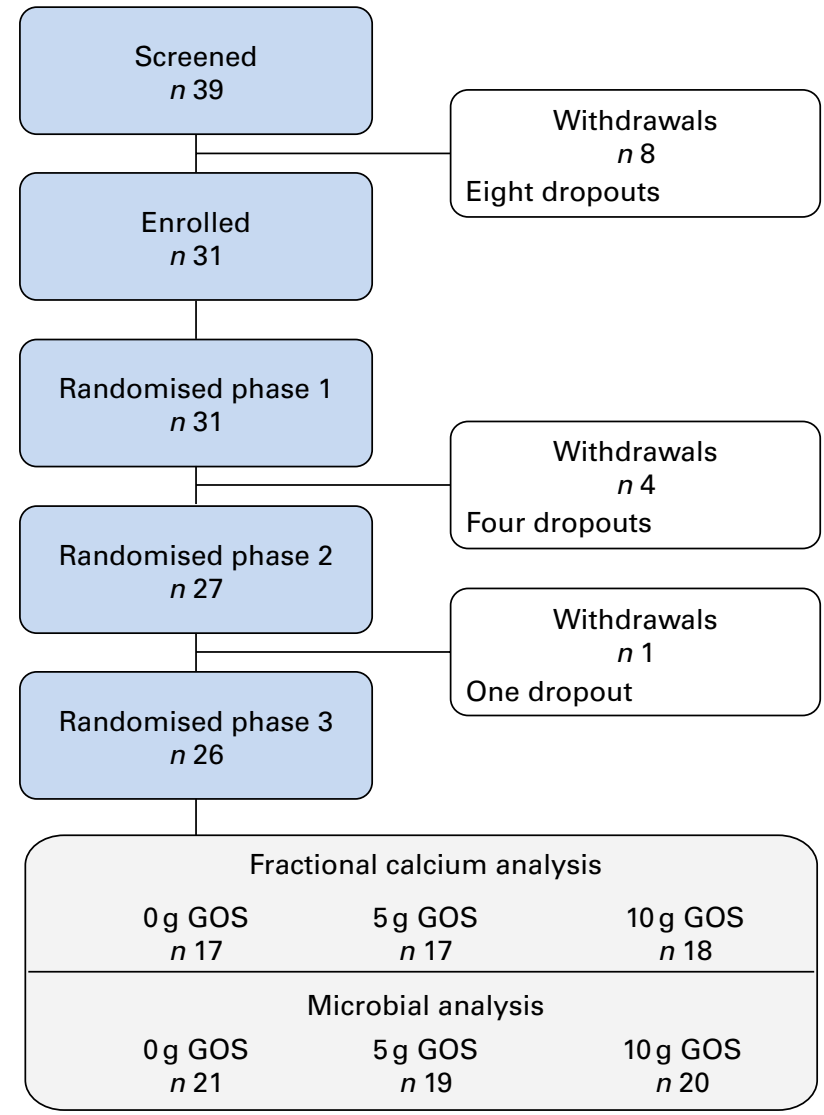

Fig. 1. Flow of participants through each phase of the study. Fractional calcium analysis: variation in the number of subjects is due to the omission of data from phases in which participants were non-compliant, taking antibiotics (subject data were excluded for the phase during which antibiotics were prescribed as well as the following phase to account for residual effects) or if calculated fractional calcium absorption was $>1 \cdot 00$. Microbial analysis: difference in the final number of subjects due to non-compliant faecal sample collection. GOS, galacto-oligosaccharides. (A colour version of this figure can be found online at http://www.journals.cambridge.org/bjn.)

\section{Self-reported gastrointestinal symptoms}

Mean scores for abdominal pain, bloating, flatulence and diarrhoea were all below 1, which represented hardly any gastrointestinal symptom (Fig. 2). There were no significant differences among the groups receiving 0,5 or $10 \mathrm{~g} / \mathrm{d}$ of GOS, for any of these symptoms. Bowel movement frequency was reported as every other day to once per $\mathrm{d}$ for all treatment groups and did not change with weekly surveys. Mean bowel movement consistency was reported normal across all the three phases with no differences across the 3 weeks of each treatment period.

\section{Methane producers}

Of the study participants, eight were confirmed as methane producers with a methane threshold $>1$ parts per million. $\chi^{2}$ analysis indicated that the GOS-induced increase or decrease of fractional $\mathrm{Ca}$ absorption was not related to the methane status $(P=0 \cdot 71)$. 
Table 3. Baseline anthropometric and biochemical characteristics of the participants

(Mean values and standard deviations, $n$ 31)

\begin{tabular}{|c|c|c|}
\hline Characteristics & Mean & SD \\
\hline Age (years) & 11.7 & $1 \cdot c$ \\
\hline Height (cm) & $151 \cdot 1$ & $9 \cdot 1$ \\
\hline Weight (kg) & $43 \cdot 6$ & 9.9 \\
\hline BMI $\left(\mathrm{kg} / \mathrm{m}^{2}\right)$ & $18 \cdot 9$ & $2 \cdot 6$ \\
\hline BMI for age, percentile & $57 \cdot 3$ & $24 \cdot 3$ \\
\hline Soluble transferrin receptor* $(\mathrm{nmol} / \mathrm{l})$ & $19 \cdot 4$ & 3.6 \\
\hline C-reactive protein* $(\mathrm{mg} / \mathrm{l})$ & 0.5 & 1.0 \\
\hline Ferritin* $(\mathrm{ng} / \mathrm{ml})$ & $27 \cdot 7$ & $14 \cdot 2$ \\
\hline $\mathrm{Hb}^{*}(\mathrm{~g} / \mathrm{l})$ & 134 & $6 \cdot 0$ \\
\hline Haematocrit* $(\%)$ & 39.6 & 1.8 \\
\hline Serum $Z n^{\star}(\mu g / l)$ & 827 & 169 \\
\hline $4 \%$ Radius, total area $\left(\mathrm{mm}^{2}\right)$ & 231.5 & 59.2 \\
\hline $4 \%$ Radius, total BMC $(\mathrm{mg} / \mathrm{mm})$ & 64.7 & $12 \cdot 8$ \\
\hline $4 \%$ Radius, total BMD $\left(\mathrm{mg} / \mathrm{cm}^{3}\right)$ & 285.4 & $45 \cdot 0$ \\
\hline $4 \%$ Radius, cortical thickness $(\mathrm{mm})$ & 1.4 & 0.2 \\
\hline $4 \%$ Tibia, total area $\left(\mathrm{mm}^{2}\right)$ & $734 \cdot 0$ & $144 \cdot 7$ \\
\hline $4 \%$ Tibia, total BMC $(\mathrm{mg} / \mathrm{mm})$ & 203.5 & $41 \cdot 0$ \\
\hline $4 \%$ Tibia, total BMD $\left(\mathrm{mg} / \mathrm{cm}^{3}\right)$ & 278.5 & $30 \cdot 5$ \\
\hline $4 \%$ Tibia, cortical thickness (mm) & 1.9 & $0 \cdot 1$ \\
\hline
\end{tabular}

BMD, bone mineral density.

${ }^{*}$ Reference ranges: soluble transferrin receptor, $8.8-28.1 \mathrm{nmol} / \mathrm{l}$; C-reactive protein, $0.0-4.0 \mathrm{mg} / \mathrm{l}$; ferritin, $10.0-291.0 \mathrm{ng} / \mathrm{ml} ; \mathrm{Hb}, 120-150 \mathrm{~g} / \mathrm{l}$; haematocrit, $35 \cdot 0-45 \cdot 0 \%$; serum Zn, $700-1500 \mu \mathrm{g} / \mathrm{l}$.

\section{Fractional calcium absorption}

Fractional $\mathrm{Ca}$ absorption data, determined in four consecutive $12 \mathrm{~h}$ urine aliquots, suggested a significant $(P=0 \cdot 0132)$ treatment effect (Table 5). Over all time points, 5 and $10 \mathrm{~g}$ GOS/d had significantly greater effects on fractional $\mathrm{Ca}$ absorption, but the response was not dose-dependent. Three-compartment kinetic modelling resulted in mean fractional $\mathrm{Ca}$ absorption over the $48 \mathrm{~h}$ test period for control, 5 and $10 \mathrm{~g}$ GOS of 0.393 (SD 0.092), 0.444 (sD 0.086) and 0.419 (SD 0.099), respectively. In turn, the improvements to fractional $\mathrm{Ca}$ absorption with the $5 \mathrm{~g}$ and $10 \mathrm{~g}$ treatments accounted for increases of 13.0 and $6.6 \%$. Linear analysis also revealed a significant time effect $(P<0 \cdot 0001)$ for fractional Ca absorption (Fig. 3). $\mathrm{Ca}$ absorption peaked in the $24-36 \mathrm{~h}$ urine aliquot, resulting in significantly greater absorption than the earlier time points. Fractional $\mathrm{Ca}$ absorption remained elevated in the final urine aliquot $(36-48 \mathrm{~h})$, but did not differ significantly from the $24-36 \mathrm{~h}$ aliquot. Urinary total $\mathrm{Ca}$ excretion was unaffected by the presence of GOS (Table 5).

\section{Microbial analysis and bacterial community}

There were only twenty subjects included in the microbial analysis section because some subjects did not produce any faecal samples during the clinic visits or they were taking antibiotics. Of these twenty subjects, all but one submitted a faecal sample before the start of the study treatments $(\mathrm{N})$. This subject was kept in the present analysis. During the clinic visit, the number of samples collected from each subject for each treatment varied from one to three, and the total number of samples available for microbiota analysis varied from three to eight per subject across all treatments and baseline.

PCR-DGGE profiles from twenty adolescent girls were produced from samples collected before $(\mathrm{N})$ and after 3 weeks of consuming the GOS treatments $(0,5$ and $10 \mathrm{~g} / \mathrm{d})$ using $16 \mathrm{~S}$ rRNA gene universal primers. Regardless of the treatment, the number of bands in a faecal bacterial community profile was similar, ranging from 16 to 35 (Table 6). There was no significant difference in average band numbers in profiles from subjects after they consumed the different GOS treatments, indicating that total dominant bacterial population numbers within communities were not influenced by GOS.

Similarities between fingerprint profiles within and between the subjects are illustrated in the dendrogram (using UPGMA; Unweighted Pair Group Method with Arithmetic Mean) of Dice similarity values (Fig. 4). A comparison of PCR-DGGE profiles from all subjects indicates that there is more similarity within each individual than by treatments (Fig. 4). Although specific bands distinguished treatments within an individual, these bands were not common to all subjects undergoing similar GOS treatments.

Dice similarity values between subjects typically ranged from 15 to $87 \%$ after the treatment and 19 to $74 \%$ before starting any treatment. Dice similarity values within subjects typically ranged from 55 to $100 \%$, with the exception of one subject showing a similarity of $34 \%$. In addition, the UPGMA clustering of the PCR-DGGE profiles within each subject indicated that the patterns were grouped by treatment (Fig. 4). This trend was seen in all the subjects examined.

\section{Bifidobacteria quantification}

Quantitative PCR using bifidobacteria-specific primers indicated that all subjects in the present study contained detectable levels of this bacterial group before and after the dietary treatment. After the dietary intervention, significant increases in bifidobacteria occurred (Table 7). The change in bifidobacteria, independent of the unit used, was significantly greater in subjects consuming the $5 \mathrm{~g} / \mathrm{d}$ of GOS treatment compared with the control and $10 \mathrm{~g} / \mathrm{d}$ of GOS treatments. The total bacterial copies were only significantly different when expressed as copies/ng faeces $(P=0.0043)$ with the $5 \mathrm{~g} / \mathrm{d}$ of GOS treatment resulting in greater amounts than the $10 \mathrm{~g}$ GOS and control treatments.

Table 4. Habitual dietary intakes of participants from $6 \mathrm{~d}$ diet records* (Mean values and standard deviations; minimum and maximum values)

\begin{tabular}{lcccc}
\hline & Mean & SD & Minimum & Maximum \\
\hline Energy intake $(\mathrm{kJ} / \mathrm{d}) \dagger$ & 8155 & 2920 & 1121 & 17443 \\
Ca intake $(\mathrm{mg} / \mathrm{d}) \dagger$ & 1010 & 260 & 461 & 1552 \\
Dietary fibre intake $(\mathrm{g} / \mathrm{d}) \dagger$ & 13.8 & 7.4 & 0.7 & 43.2 \\
Soluble fibre $(\mathrm{g} / \mathrm{d}) \dagger$ & 4.5 & 3.1 & 0.3 & 24.8 \\
Insoluble fibre $(\mathrm{g} / \mathrm{d}) \dagger$ & 9.2 & 5.1 & 0.4 & 30.8 \\
\hline
\end{tabular}

* Only values for individuals who completed the $6 \mathrm{~d}$ diet record were included $(n 27)$ $\dagger$ Average intake was estimated by averaging daily values from the $6 \mathrm{~d}$ diet record. 
(a)

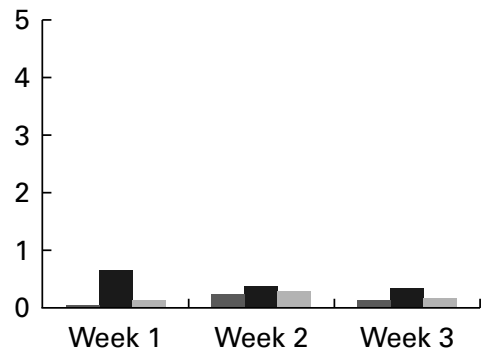

(c)

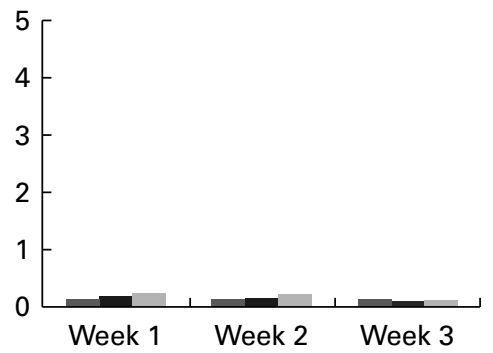

(e) 5

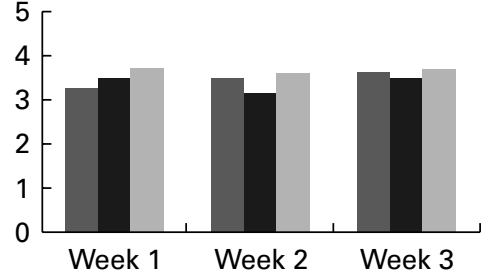

(b)

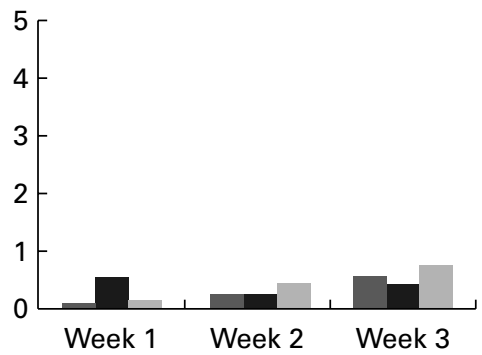

(d)

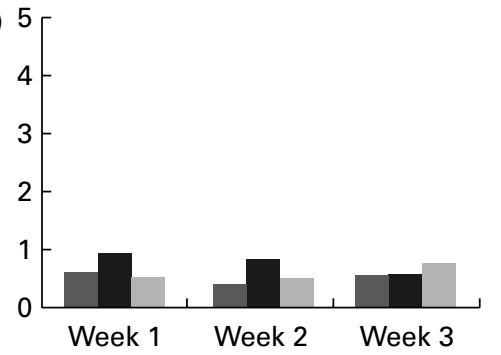

(f)

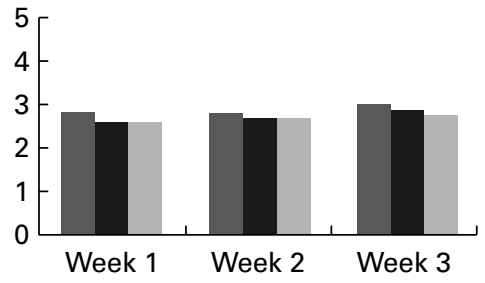

Fig. 2. Self-reported mean gastrointestinal symptoms collected from weekly surveys. (a) Bloating, (b) abdominal pain, (c) diarrhoea, (d) flatulence, (e) bowel movement frequency and (f) bowel movement consistency. Scoring key for (a)-(d): 0, none; 1, slight; 2, mild; 3, moderate; 4, moderately severe; 5 , severe. Frequency scoring key for (e) and (f): 0 , no bowel movement; 1, once/week; 2, twice/week; 3, every other day; 4, once/d; 5 , more than once/d. Consistency key for

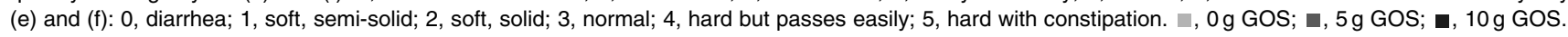

\section{Determinants of calcium absorption}

Over all time points, the difference in fractional Ca absorption between the GOS and control treatments was inversely correlated with fractional $\mathrm{Ca}$ absorption during the control period $(r-0.51, P<0.0001)$. Fractional Ca absorption on the control was significantly correlated with fractional $\mathrm{Ca}$ absorption response to $5 \mathrm{~g} / \mathrm{d}$ of GOS at $12 \mathrm{~h}(r-0.65, P=0.03), 24 \mathrm{~h}$ $(r-0.70, P=0.02)$ and $48 \mathrm{~h}(r-0.66, P=0.03)$ (Table 8) but not for the fractional Ca absorption response to $10 \mathrm{~g} / \mathrm{d}$ of GOS.

\section{Discussion}

Adaptation to GOS supplementation for 3 weeks significantly affected $\mathrm{Ca}$ absorption and faecal microbe profiles in preadolescent girls habitually consuming at or near the daily

Table 5. Comparison of mean calcium absorption from the general linear model evaluating all $12 \mathrm{~h}$ urine aliquots together*

(Mean values and standard deviations)

\begin{tabular}{|c|c|c|c|c|c|c|c|c|c|c|c|}
\hline \multirow[b]{2}{*}{ Outcome measure } & \multirow[b]{2}{*}{ Time (h) } & \multicolumn{3}{|c|}{$0 \mathrm{~g} \mathrm{GOS} / \mathrm{d}$} & \multicolumn{3}{|c|}{$5 \mathrm{~g} \mathrm{GOS} / \mathrm{d}$} & \multicolumn{3}{|c|}{$10 \mathrm{~g} \mathrm{GOS} / \mathrm{d}$} & \multirow[b]{2}{*}{$P$ (treatment effect } \\
\hline & & $n$ & Mean & SD & $n$ & Mean & SD & $n$ & Mean & SD & \\
\hline \multirow[t]{4}{*}{ Fractional Ca absorption } & 12 & 17 & 0.31 & 0.08 & 17 & 0.35 & 0.07 & 18 & 0.34 & 0.08 & \\
\hline & 24 & 17 & 0.39 & 0.08 & 17 & 0.44 & 0.08 & 18 & 0.42 & 0.13 & $0 \mathrm{~g}<5 \mathrm{~g}, 10 \mathrm{~g}$ \\
\hline & 36 & 17 & 0.43 & 0.12 & 16 & 0.46 & 0.09 & 18 & 0.44 & 0.13 & 0.0132 \\
\hline & 48 & 17 & 0.41 & 0.08 & 16 & 0.43 & 0.09 & 18 & 0.41 & 0.14 & \\
\hline \multirow[t]{4}{*}{ Urinary Ca excretion (mg/12h) } & 12 & 17 & 40 & 29 & 17 & 36 & 28 & 18 & 40 & 24 & \\
\hline & 24 & 17 & 39 & 19 & 17 & 34 & 25 & 18 & 42 & 21 & 0.2506 \\
\hline & 36 & 16 & 35 & 20 & 16 & 32 & 22 & 18 & 37 & 18 & \\
\hline & 48 & 17 & 40 & 25 & 17 & 35 & 29 & 18 & 44 & 18 & \\
\hline
\end{tabular}

GOS, galacto-oligosaccharides.

*Urine sample aliquots are $12(0-12), 24(12-24), 36(24-36)$ and $48(36-48)$ h. Four subjects were treated with antibiotics during phase 2 . Data from phase 2 and phase 3 were excluded from the analysis for these participants. Phases where subjects were non-compliant, measured by urine creatinine levels, were excluded from the analysis. Six subjects were excluded for non-compliance measured by urine creatinine. Two specific time points were excluded from the analysis for individual subjects when fractional absorption values were physiologically implausible (fractional absorption that was negative or greater than 1.00 ). 


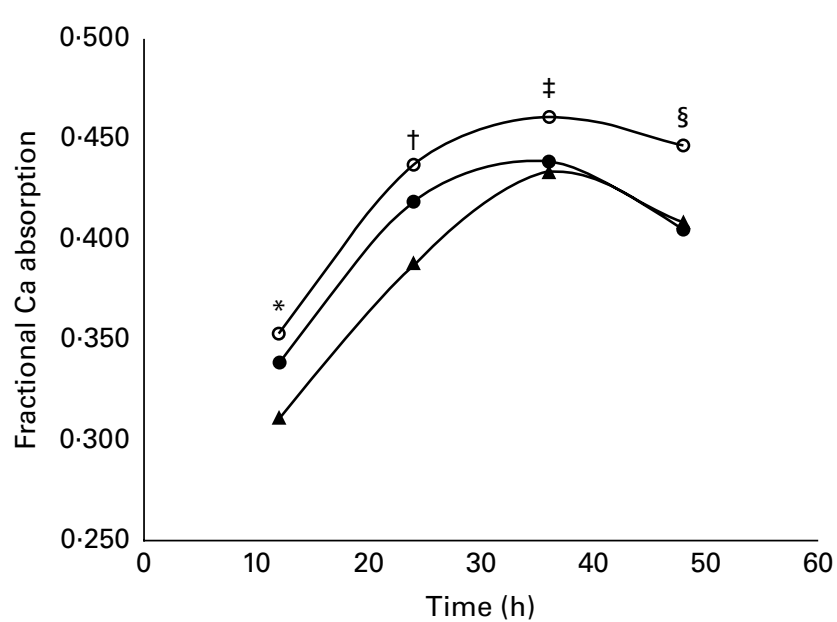

Fig. 3. Effect of time on mean fractional calcium absorption measured in $12 \mathrm{~h}$ urine aliquots. Girls treated twice daily with $2.5 \mathrm{~g}$ galacto-oligosaccharides (GOS, $5 \mathrm{~g},-\longrightarrow$ ); girls treated twice daily with $5 \mathrm{~g}$ GOS $(10 \mathrm{~g}, \longrightarrow$ ); girls treated twice daily with $0 \mathrm{~g}$ GOS $(0 \mathrm{~g}, \multimap)$. General linear analysis was used to assess the effect of time on fractional calcium absorption $(P<0.0001)$ and least significant difference post hoc comparisons were used to compare differences in fractional calcium absorption by time point (time effect for all treatments: $\left.{ }^{*} 12 \mathrm{~h}, \dagger 24 \mathrm{~h}, \ddagger 36 \mathrm{~h}, \S 48 \mathrm{~h} ; P<0.05\right)$

recommended $\mathrm{Ca}$ intake. There was no dose-response effect; treatment with $5 \mathrm{~g} / \mathrm{d}$ of GOS elicited maximal benefit on fractional $\mathrm{Ca}$ absorption and bifidobacteria levels in the lower gut.

\section{Calcium absorption}

We observed a significant increase in $\mathrm{Ca}$ absorption with the consumption of $5 \mathrm{~g} / \mathrm{d}$ of GOS. This suggests that a dose of $5 \mathrm{~g}$ GOS/d may be more effective at increasing Ca absorption in growing, pre-menarcheal girls than $10 \mathrm{~g} / \mathrm{d}$ of GOS.

Mean fractional $\mathrm{Ca}$ absorption values from our model that used all time points for the control, 5 and $10 \mathrm{~g} / \mathrm{d}$ of GOS treatments were 0.393 (SD 0.092), 0.444 (SD 0.086) and 0.419 (SD 0.099), respectively. The benefit of treatment with 5 and $10 \mathrm{~g} / \mathrm{d}$ of GOS was 13.0 and $6.6 \%$, respectively. This is of similar magnitude to the $8.3 \%$ increase in fractional Ca absorption in postmenopausal women consuming $5 \mathrm{~g} / \mathrm{d}$ of lactulose ${ }^{(31)}$. This study is the only other study to investigate a doseresponse using 5 and $10 \mathrm{~g}$ non-digestible oligosaccharide treatments, but unlike the present study in girls, the postmenopausal women consuming $10 \mathrm{~g} / \mathrm{d}$ of lactulose had an additional $16 \cdot 2 \%$ increase over the $5 \mathrm{~g}$ treatment ${ }^{(31)}$. Whether the lack of a dose-response effect in girls was due to the difference in age of the two study groups or is an anomaly requires further research.

In animals, dose-dependent effects on Ca absorption have been reported for inulin-type fructans ${ }^{(7)}$, lactulose ${ }^{(32)}$ and galacto-oligosaccharides $^{(13)}$. Although GOS effects on $\mathrm{Ca}$ absorption were not dose-dependent in the present study, data in rats have shown that GOS treatment has positive effects on bone independent of Ca absorption ${ }^{(11-13)}$. Trabecular-rich bones received the greatest benefit among 4-week-old male rats fed $0-8 \%$ GOS through decreased caecal $\mathrm{pH}$, increased caecal wall and content weight, and a greater proportion of bifidobacteria ${ }^{(13)}$. In addition, we previously reported that soluble maize fibre and soluble fibre dextrin positively influenced measures of bone geometry and strength in growing rats, independent of changes in Ca absorption ${ }^{(33)}$. Lactulose stimulated $\mathrm{Ca}$ absorption in caecectomised rats ${ }^{(32)}$, as the caecum is not essential for the stimulatory effects of vitamin $\mathrm{D}^{(34)}$. In relation to prebiotics, fructo-oligosaccharide influences $\mathrm{Ca}$ absorption in the caecum of rats ${ }^{(35)}$, but adaptation to the treatment has been reported in rats after $28-30 \mathrm{~d}$ of fructo-oligosaccharide feeding ${ }^{(10)}$, presumably through the down-regulation of the vitamin D endocrine system. Perhaps the independent bone effects seen in rats fed soluble fibres are the result of adaptation of the vitamin D system after 12 weeks of treatment. Effects on bone changes are not available in the present study cohort as bone measures were only assessed at baseline, and longer study duration is necessary to measure changes in human bone, making it difficult to speculate on the skeletal effects of GOS in the present study. Similarly, while vitamin D status did not differ after the treatment, other markers of the vitamin D endocrine system were not assessed.

The measurement of fractional $\mathrm{Ca}$ absorption in the urine over $48 \mathrm{~h}$ by $12 \mathrm{~h}$ urine samples allowed us to determine how absorption was affected by GOS as Ca was transported along the gut. Previous research has suggested that non-digestible oligosaccharides are poorly absorbed in the small intestine and later undergo acidic fermentation in the caecum and colon of rats which improves $\mathrm{Ca}$ absorption in the large intestine ${ }^{(36)}$. Van den Heuvel et al. ${ }^{(37)}$ found that a $36 \mathrm{~h}$, rather than $24 \mathrm{~h}^{(15)}$, urine collection was necessary to measure this late fraction of absorbed $\mathrm{Ca}$. We observed a peak in fractional $\mathrm{Ca}$ absorption in the urine pool collected between 24 and $36 \mathrm{~h}$, which supports lower gut effects.

The approximate $10 \%$ increase in absorption with 5 and $10 \mathrm{~g} / \mathrm{d}$ of GOS in the present study equates to an additional $130 \mathrm{mg} / \mathrm{d}$ or $49 \mathrm{~g} /$ year of Ca being absorbed and available for deposition into the bone. Assuming that total body $\mathrm{Ca}$ in an adult skeleton is about $900 \mathrm{~g}$, the increase we observed with GOS would account for approximately 5.4\% of the total skeleton. A long-term intervention reported a $6 \%$ increase in Ca absorption in boys and girls consuming $8 \mathrm{~g} / \mathrm{d}$ of Synergy $1{ }^{\circledR}$ (Orafti), which accounted for an additional absorption of $55 \mathrm{mg} \mathrm{Ca} / \mathrm{d}^{(16)}$. This study also resulted in a $35 \mathrm{~g}$ difference in bone mineral content after 1 year.

Table 6. Average number of bands in bacterial PCRdenaturing gradient gel electrophoresis fingerprint profiles before $(\mathrm{N})$ and after the dietary galacto-oligosaccharide treatments $(0,5 \text { and } 10 \mathrm{~g} / \mathrm{d})^{*}$

(Number of bands and standard deviations)

\begin{tabular}{lccc}
\hline & & \multicolumn{2}{c}{ Average band } \\
\cline { 3 - 4 } Treatments & Range band number & Number & SD \\
\hline Baseline $(\mathrm{N})$ & $17-33$ & $22 \cdot 6$ & 3.8 \\
$0 \mathrm{~g} / \mathrm{d}$ & $19-35$ & $26 \cdot 0$ & $3 \cdot 8$ \\
$5 \mathrm{~g} / \mathrm{d}$ & $18-32$ & $25 \cdot 3$ & 3.7 \\
$10 \mathrm{~g} / \mathrm{d}$ & $15-33$ & 23.9 & 4.7
\end{tabular}

* No significant difference in band numbers $(P>0.05)$. 


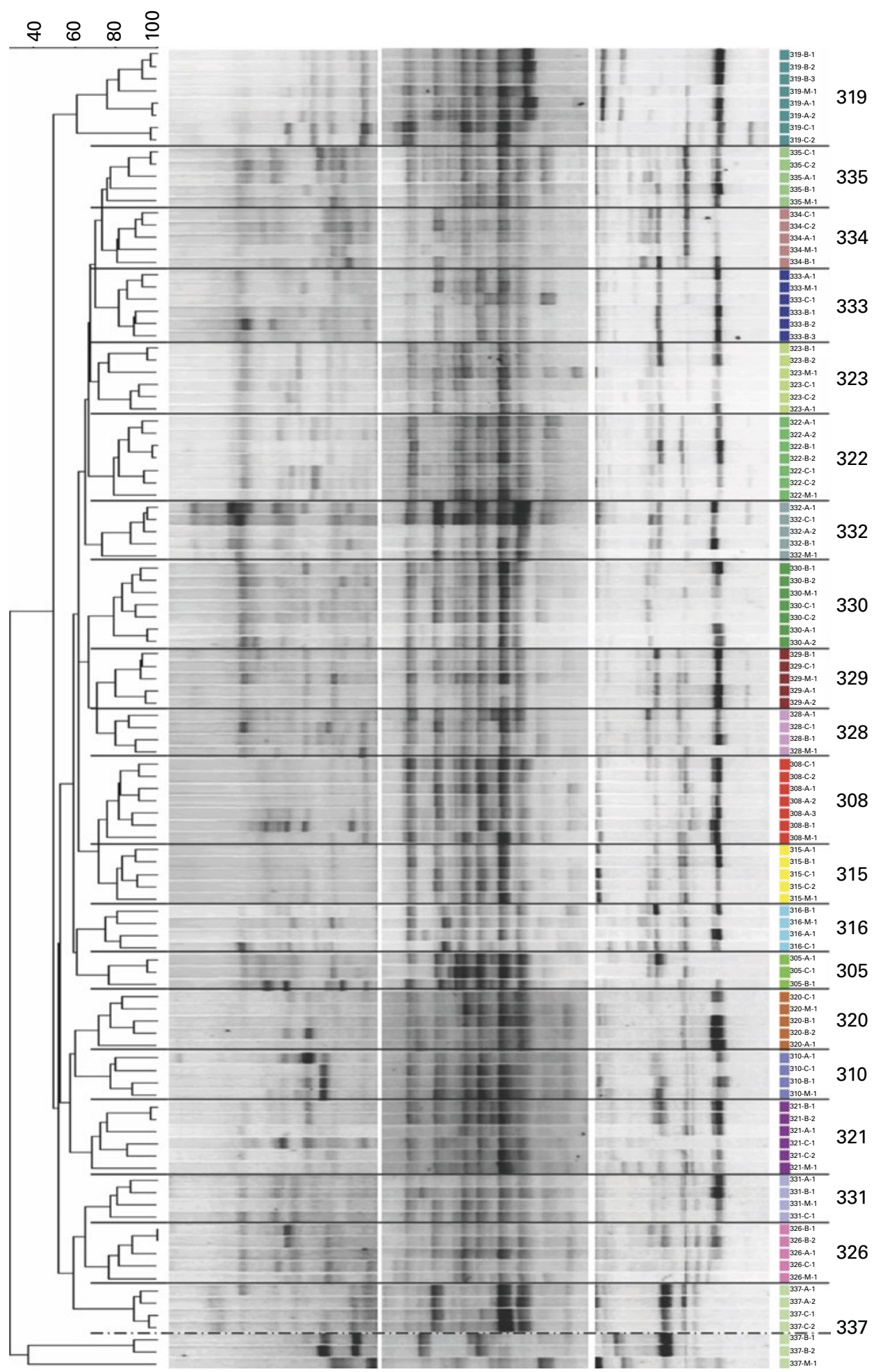

Fig. 4. Dendrogram of the denaturing gradient gel electrophoresis profiles of adolescent girls before $(\mathrm{N})$ and after the three galacto-oligosaccharides treatments (A, $5 \mathrm{~g} \mathrm{GOS} / \mathrm{d} ; \mathrm{B}, 10 \mathrm{~g} \mathrm{GOS} / \mathrm{d}$; C, control). Cluster analysis (UPGMA) using the Dice similarity index. Profiles were from all faecal samples collected on the last $3 \mathrm{~d}$ of each treatment. Bands were separated using the denaturing gradients $35-56$ and $25-75 \%$. (A colour version of this figure can be found online at http://www.journals.cambridge.org/bjn). 
Table 7. Changes in bifidobacteria and total bacteria $16 \mathrm{~S}$ ribosomal RNA gene copy numbers in subjects after the treatment with galacto-oligosaccharides (GOS) $\dagger$

(Mean values and standard deviations)

\begin{tabular}{|c|c|c|c|c|c|c|c|}
\hline \multirow[b]{2}{*}{ Measurement change from baseline } & \multicolumn{2}{|c|}{$0 \mathrm{~g} \mathrm{GOS}(n 21)$} & \multicolumn{2}{|c|}{$5 \mathrm{~g} \mathrm{GOS}(n 19)$} & \multicolumn{2}{|c|}{$10 \mathrm{~g}$ GOS $(n 20)$} & \multirow[b]{2}{*}{$P$} \\
\hline & Mean & SD & Mean & SD & Mean & SD & \\
\hline Bifidobacteria ( $10^{5}$ copies/ng DNA) & $2 \cdot 19^{a}$ & 3.88 & $5 \cdot 05^{\mathrm{b}}$ & $4 \cdot 16$ & $2 \cdot 68^{a}$ & $3 \cdot 36$ & $<0.0069$ \\
\hline Total bacteria ( $10^{5}$ copies/ng DNA) & 0.96 & $2 \cdot 33$ & 1.30 & $2 \cdot 11$ & 1.09 & $2 \cdot 12$ & $\mathrm{NS}^{*}$ \\
\hline Bifidobacteria ( $10^{7}$ copies $/ \mathrm{mg}$ faeces) & $0.49^{\mathrm{a}}$ & 3.91 & $5 \cdot 17^{b}$ & 4.04 & $2.57^{\mathrm{a}}$ & 3.37 & $<0.0007$ \\
\hline Total bacteria ( $10^{7}$ copies $/ \mathrm{mg}$ faeces) & $0.91^{\mathrm{a}}$ & $2 \cdot 25$ & $1 \cdot 33^{\mathrm{b}}$ & $2 \cdot 17$ & $1.05^{a, b}$ & $2 \cdot 18$ & 0.0043 \\
\hline$\%$ Bifidobacteria of total bacteria & $10 \cdot 89^{\mathrm{a}}$ & 13.86 & $22 \cdot 80^{\mathrm{b}}$ & $15 \cdot 74$ & $11.54^{\mathrm{a}}$ & $14 \cdot 20$ & $<0.0272$ \\
\hline
\end{tabular}

a,b,c Mean values with unlike superscript letters were significantly different for treatment effects $(P<0.05)$

${ }^{*}$ Mean values were not significantly different for treatment effects $(P>0.05)$.

† Comparisons were performed using linear models and post hoc $t$ test. Quantitative PCR efficiencies $>90 \%, R^{2}$ of standard curves $>0.996$ with slopes ranging from -3.181 to -3.586 .

Mean Ca excretion measured in the $12 \mathrm{~h}$ urine aliquots ranged from 32 to $44 \mathrm{mg}$ and was unaffected by treatment $(P=0 \cdot 25)$. Thus, the increased $\mathrm{Ca}$ absorbed is not excreted and should lead to improved $\mathrm{Ca}$ retention. In rats, GOS increased $\mathrm{Ca}$ absorption dose-dependently, which led to increased $\mathrm{Ca}$ retention ${ }^{(13)}$. In postmenopausal women, $\mathrm{Ca}$ excretion was not altered with transgalacto-oligosaccharide intakes of $20^{(14)}$ or $5 \mathrm{~g} / \mathrm{d}$ and $10 \mathrm{~g} / \mathrm{d}$ of lactulose ${ }^{(31)}$. Similarly, no relationship was seen between $\mathrm{Ca}$ absorption and urinary Ca excretion in adolescent boys consuming $15 \mathrm{~g} / \mathrm{d}$ of oligofructose $^{(37)}$.

Few studies have investigated $\mathrm{Ca}$ absorption in response to modest prebiotic consumption such as the $5 \mathrm{~g}$ treatment used in the present study and the lactulose study described above in postmenopausal women ${ }^{(31)}$. Griffin et al. ${ }^{(38)}$ reported an $18 \%$ increase in $\mathrm{Ca}$ absorption in 11-14-year-old girls in response to consuming $8 \mathrm{~g} / \mathrm{d}$ of an inulin-oligofructose mixture. Similarly, Ca absorption in 9-13-year-old girls and boys consuming $8 \mathrm{~g} / \mathrm{d}$ of a mixed short- and long-chain inulintype fructan was $8.5 \%$ greater than that on the control ${ }^{(16)}$. Conversely, cereal fortified with $9 \mathrm{~g} / \mathrm{d}$ of oligofructoseenriched inulin as part of a diet containing approximately $1500 \mathrm{mg} / \mathrm{d}$ of $\mathrm{Ca}$ in 11-13-year-old girls did not increase Ca absorption compared with a cereal without the non-digestible oligosaccharides $^{(39)}$. Most studies have used $>10 \mathrm{~g}$ fibre ${ }^{(14,15,36,40-45)}$. Fructan fibres have also been proven effective in lower amounts between 1.1 and $1.75 \mathrm{~g} / \mathrm{d}$ in postmenopausal women and young adults ${ }^{(46,47)}$. However, these fructans were combined with other possible absorption enhancers such as casein phosphopeptides. Therefore, further study of low prebiotic doses is important to translate to practical levels for consumers.

\section{Gut microbe analysis}

Bifidobacteria as a percentage of total bacteria increased with GOS treatment. Others have reported increases in faecal bifidobacteria and Lactobacillus species in animal models ${ }^{(48,49)}$ and human subjects ${ }^{(50,51)}$ in response to prebiotic consumption generally, and specifically with GOS consumption $^{(4,13,52,53)}$, and a dose-response effect was observed in both rats ${ }^{(13)}$ and adult human subjects ${ }^{(54)}$. Our lack of a dose-response effect of the microbiota to GOS may represent a difference between adolescents and adults or a spurious observation. A potential threshold effect may also explain the lack of a dose-response where the difference in bifidobacteria proportion between the GOS and control treatments was inversely correlated with bifidobacteria proportions during the control period $(r-0.54, P=0.0001)$. While GOS increased the proportion of bifidobacteria, inverse correlation suggests that individuals with naturally higher quantities of bifidobacteria may only experience an increase up to a certain threshold level.

\section{Determinants of calcium absorption}

Few studies have attempted to explore potential determinants of $\mathrm{Ca}$ absorption in relation to prebiotic consumption. Using multiple regression analysis, Griffin et al. ${ }^{(30)}$ found Ca absorption on placebo as the only factor that explained the difference in fractional absorption with Synergy $1^{\circledR}$ and placebo. Other factors included in the model, which have known associations with $\mathrm{Ca}$ absorption including, weight, height, age, race and Tanner stage, did not explain the beneficial response of Synergy ${ }^{\circledR}$. This finding is similar to the results from the present study as the fractional absorption response with $5 \mathrm{~g} / \mathrm{d}$ of GOS was inversely correlated with fractional Ca absorption on control at 12, 24 and $48 \mathrm{~h}(r<-0.65$, $P<0.05)$, but not in response to $10 \mathrm{~g} / \mathrm{d}$ of GOS over all time intervals. No correlations between the benefit of GOS and variables related to diet, anthropometrics, physical fitness and gut bacteria were found; however, this may be due to the small variable ranges and sample size.

Table 8. Galacto-oligosaccharides (GOS) response and fractional calcium absorption correlations ${ }^{\star}$

\begin{tabular}{|c|c|c|c|c|c|c|}
\hline \multirow{2}{*}{$\begin{array}{l}\text { Ca absorption on control } \\
\text { Urine aliquot }\end{array}$} & \multicolumn{3}{|c|}{$\begin{array}{l}\text { Change in } \mathrm{Ca} \\
\text { absorption with } \\
5 \mathrm{~g} \mathrm{GOS} / \mathrm{d}\end{array}$} & \multicolumn{3}{|c|}{$\begin{array}{l}\text { Change in } \mathrm{Ca} \\
\text { absorption with } \\
10 \mathrm{~g} \mathrm{GOS} / \mathrm{d}\end{array}$} \\
\hline & $r$ & $P$ & $n$ & $r$ & $P$ & $n$ \\
\hline $0-12 \mathrm{~h}$ urine & -0.65 & 0.03 & 11 & -0.41 & 0.19 & 12 \\
\hline $12-24 \mathrm{~h}$ urine & -0.7 & 0.02 & 11 & -0.4 & 0.2 & 12 \\
\hline $24-36$ h urine & -0.54 & 0.11 & 10 & -0.42 & 0.17 & 12 \\
\hline $36-48 \mathrm{~h}$ urine & -0.66 & 0.03 & 11 & -0.4 & 0.2 & 12 \\
\hline
\end{tabular}

* Pearson's correlations $(P<0.05)$. 
The strengths of the present study included the cross-over design and controlled diets during the assessment of fractional Ca absorption by dual stable isotope techniques. Additionally, product compliance during the present study suggests the ease and feasibility of consuming GOS in daily life. This is especially important because prebiotics only cause transient changes in gut microbiota and therefore $\mathrm{Ca}$ absorption also. The high acceptance of GOS in the present study suggests that individuals could easily maintain consumption in the long term to obtain prolonged benefits for bone health. The limitations of the present study include the small sample size. Therefore, it was not possible to further explore the determinants of GOS-induced increases in $\mathrm{Ca}$ absorption in a multivariate model. Moreover, the number of faecal samples for microbiota fingerprint profiling was limited due to the shortened clinical visits.

\section{Conclusion}

In pre-menarcheal girls, twice daily consumption of GOS had positive, but no dose-response, effects on fractional Ca absorption and gut bifidobacteria. The response to GOS in fractional Ca absorption occurred as late phase absorption between 24 and $36 \mathrm{~h}$, characteristic of lower gut absorption. Supplementation with $5 \mathrm{~g} / \mathrm{d}$ of GOS improved Ca absorption and may increase peak bone mass accrual during adolescence by influencing microbial communities in the lower gut.

\section{Acknowledgements}

The present study was supported by FrieslandCampina, Stationsplein 4, Amersfoort, The Netherlands. The authors' responsibilities were as follows: C. M. Weaver, B. R. M., C. H. N., E. G. H. M. v. d. H., M. H. C. S., G. P. M. and L. D. M. designed the study; C. M. Whisner, B. R. M., C. H. N. and C. M. Weaver carried out the study; C. M. Whisner, B. R. M. and C. H. N. analysed the data; C. M. Whisner, C. M. Weaver and C. H. N. prepared the manuscript; B. R. M. assisted in writing the manuscript. All authors evaluated the manuscript and contributed their comments. E. G. H. M. v. d. H. and M. H. C. S. are employees of FrieslandCampina and C. M. Weaver serves on the Advisory Board of Pharmavite. All other authors have no conflicts of interest.

\section{References}

1. Food and Agriculture Organization, World Health Organization (2001) The Food and Agriculture Organization of the United Nations and the World Health Organization Joint FAO/WHO Expert Consultation on Evaluation of Health and Nutritional Properties of Probiotics in Food Including Powder Milk with Live Lactic Acid Bacteria. FAO/WHO Report no. 10-1-2001.

2. Bailey RL, Dodd KW, Goldman JA, et al. (2010) Estimation of total usual calcium and vitamin D intakes in the United States. J Nutr 140, 817-822.

3. Park CY \& Weaver CM (2011) Calcium and bone health: influence of prebiotics. Funct Food Rev 3, 62-72.

4. Bouhnik Y, Flourie B, D'Agay-Abensour L, et al. (1997) Administration of transgalacto-oligosaccharides increases fecal bifidobacteria and modifies colonic fermentation metabolism in healthy humans. J Nutr 127, 444-448.

5. Durand M, Cordelet C, Hannequart G, et al. (1992) In vitro fermentation of a galacto-oligosaccharide by human bacteria in continuous culture. Proc Nutr Soc 51, 6A.

6. Rémésy C, Levrat MA, Gamet L, et al. (1993) Cecal fermentations in rats fed oligosaccharides (inulin) are modulated by dietary calcium level. Am J Physiol 264, G855-G862.

7. Levrat MA, Rémésy C \& Demigné C (1991) High propionic acid fermentations and mineral accumulation in the cecum of rats adapted to different levels of inulin. J Nutr 121, $1730-1737$

8. Pérez-Conesa D, López G \& Ros G (2007) Effects of probiotic, prebiotic and symbiotic follow-up infant formulas on large intestine morphology and bone mineralization in rats. J Sci Food Agric 87, 1059-1068.

9. Rashka L \& Daniel H (2005) Diet composition and age determine the effects of inulin-type fructans on intestinal calcium absorption in rat. Eur J Nutr 44, 360-364.

10. Pérez-Conesa D, López G, Abellán P, et al. (2006) Bioavailability of calcium, magnesium and phosphorus in rats fed probiotic, prebiotic and symbiotic powder follow-up infant formulas and their effect on physiological and nutritional parameters. J Sci Food Agric 86, 2327-2336.

11. Chonan O, Matsumoto K \& Watanuki M (1995) Effects of galactooligosaccharides on calcium absorption and preventing bone loss in ovariectomized rats. Biosci Biotechnol Biochem 59, 236-239.

12. Chonan O \& Watanuki M (1996) The effect of $6^{\prime}$-galactooligosaccharides on bone mineralization of rats adapted to different levels of dietary calcium. Int J Vitam Nutr Res 66 , 244-249.

13. Weaver CM, Martin BR, Nakatsu CH, et al. (2011) Galactooligosaccharides improve mineral absorption and bone properties in growing rats through gut fermentation. J Agric Food Chem 59, 6501-6510.

14. van den Heuvel EG, Schoterman MH \& Muijs T (2000) Transgalacto-oligosaccharides stimulate calcium absorption in postmenopausal women. J Nutr 130, 2938-2942.

15. van den Heuvel EGHM, Schaafsma G, Muijs T, et al. (1998) Non-digestible oligosaccharides do not affect calcium and non-heme iron absorption in young healthy men. $A m$ J Clin Nutr 67, 445-452.

16. Abrams Sa, Griffin IJ, Hawthorne KM, et al. (2005) A combination of prebiotic short- and long-chain inulin-type fructans enhances calcium absorption and bone mineralization in young adults. Am J Clin Nutr 82, 471-476.

17. Yang YJ, Martin BR \& Boushey CJ (2010) Development and evaluation of a brief calcium assessment tool for adolescents. J Am Diet Assoc 110, 111-115.

18. Gibson GR, Macfarlane S \& Macfarlane GT (1993) Metabolic interactions involving sulphate-reducing and methanogenic bacteria in the human large intestine. FEMS Microbiol Ecol 12, 117-125.

19. Harris J \& Benedict F (1919) A Biometric Study of Basal Metabolism in Man. Washington, DC: Carnegie Institute of Washington.

20. Ashby RL, Ward KA, Roberts SA, et al. (2009) A reference database for the Stratec XCT-2000 peripheral quantitative computed tomography (pQCT) scanner in healthy children and young adults aged 6-19 years. Osteoporos Int 20, $1337-1346$.

21. Weaver CM, Rothwell AP \& Wood KV (2006) Measuring calcium absorption and utilization in humans. Curr Opin Clin Nutr Metab Care 9, 568-574. 
22. Wastney ME, Ng J, Smith D, et al. (1996) Differences in calcium kinetics between adolescent girls and young women. Am J Physiol 271, R208-R216.

23. McKay LF, Eastwood MA \& Brydon WG (1985) Methane excretion in man - a study of breath, flatus, and faeces. Gut 26, 69-74.

24. Pitt P, De Bruijn KM, Beeching MF, et al. (1980) Studies on breath methane: the effect of ethnic origins and lactulose. Gut 21, 951-959.

25. Bond JH Jr, Engel RR \& Levitt MD (1971) Factors influencing pulmonary methane excretion in man. $J$ Exp Med 133, $572-588$.

26. Ariefdjohan MW, Savaiano DA \& Nakatsu CH (2010) Optimization of DNA extraction kits for PCR-DGGE analysis of human intestinal microbial communities from fecal specimens. Nutr J 9, 23.

27. Lane DJ (1991) 16S/23S rRNA Sequencing. In Nucleic Acid Techniques in Bacterial Systematics, pp. 115-175 [E Stackebrandt and M Goodfellow, editors]. New York: John Wiley \& Sons.

28. Muyzer G, de Waal EC \& Uitterlinden AG (1993) Profiling of complex microbial populations by denaturing gradient gel electrophoresis analysis of polymerase chain reaction-amplified genes coding for 16S rRNA. Appl Environ Microbiol 59, 695-700.

29. Satokari RM, Vaughan EE, Akkermans ADL, et al. (2001) Bifidobacterial diversity in human feces detected by genusspecific PCR and denaturing gradient gel electrophoresis. Appl Environ Microbiol 67, 504-513.

30. Griffin IJ, Hicks PMD, Heaney RP, et al. (2003) Enriched chicory inulin increases calcium absorption in girls with lower calcium absorption. Nutr Res 23, 901-909.

31. Van den Heuvel EGHM, Muijs T, van Dokkum W, et al. (1999) Lactulose stimulates calcium absorption in postmenopausal women. J Bone Miner Res 14, 1211-1216.

32. Brommage R, Binacua C, Antille S, et al. (1993) Intestinal calcium absorption in rats is stimulated by dietary lactulose and other resistant sugars. J Nutr 123, 2186-2194.

33. Weaver CM, Martin BR, Story JA, et al. (2010) Novel fibers increase bone calcium content and strength beyond efficiency of large intestine fermentation. J Agric Food Chem 58, 8952-8957.

34. Brommage R, Binacua C \& Carrié AL (1995) The cecum does not participate in the stimulation of intestinal calcium absorption by calcitriol. I Steroid Biochem Mol Biol 54, $71-73$

35. Ohta A, Ohtuki M, Takizawa T, et al. (1994) Effects of fructooligosaccharides on the absorption of magnesium and calcium by cecectomized rats. Int J Vitam Nutr Res 64, 316-323.

36. Younes H, Coudray C, Bellanger J, et al. (2001) Effects of two fermentable carbohydrates (inulin and resistant starch) and their combination on calcium and magnesium balance in rats. Br J Nutr 86, 479-485.

37. Van den Heuvel EGHM, Muys T, van Dokkum W, et al. (1999) Oligofructose stimulates calcium absorption in adolescents. Am J Clin Nutr 69, 544-548.

38. Griffin IJ, Davila PM \& Abrams SA (2002) Non-digestible oligosaccharides and calcium absorption in girls with adequate calcium intakes. Br J Nutr 87, Suppl. 2, S187-S191.

39. Martin BR, Braun MM, Wigertz K, et al. (2010) Fructooligosaccharides and calcium absorption and retention in adolescent girls. J Am Coll Nutr 29, 382-386

40. Coudray C, Bellanger J, Castiglia-Delavaud C, et al. (1997) Effect of soluble or partly soluble dietary fibres supplementation on absorption and balance of calcium, magnesium, iron, and zinc in healthy young men. Eur J Clin Nutr 51, 375-380

41. Tahiri M, Tressol JC, Arnaud J, et al. (2003) Effect of short chain fructooligosaccharides on intestinal $\mathrm{Ca}$ absorption and $\mathrm{Ca}$ status in postmenopausal women: a stable isotope study. Am J Clin Nutr 77, 449-457.

42. Van den Heuvel EG, Muijs T, Brouns F, et al. (2009) Short-chain fructo-oligosaccharides improve magnesium absorption in adolescent girls with a low calcium intake. Nutr Res 29, 229-237.

43. Dahl WJ, Whiting SJ, Isaac TM, et al. (2005) Effects of thickened beverages fortified with inulin on beverage acceptance, gastrointestinal function, and bone resorption in institutionalized adults. Nutrition 21, 308-311.

44. Holloway L, Moynihan S, Abrams SA, et al. (2007) Effects of oligofructose-enriched inulin on intestinal absorption of calcium and magnesium and bone turnover markers in postmenopausal women. Br J Nutr 97, 365-372.

45. Tahiri M, Tressol JC, Arnaud J, et al. (2001) Five-week intake of short-chain fructo-oligosaccharides increases intestinal absorption and status of magnesium in postmenopausal women. J Bone Miner Res 16, 2152-2160.

46. Adolphi B, Scholz-Ahrens KE, Vrese M, et al. (2009) Short-term effect of bedtime consumption of fermented milk supplemented with calcium, inulin-type fructans and caseinphosphopeptides on bone metabolism in healthy, postmenopausal women. Eur J Nutr 48, 45-53

47. Lopez-Huertas E, Teucher B, Boza JJ, et al. (2006) Absorption of calcium from milks enriched with fructooligosaccharides caseinophosphopeptides, tricalcium phosphate, and milk solids. Am J Clin Nutr 83, 310-316.

48. Tzortzis G, Goulas AK, Gee JM, et al. (2005) A novel galactooligosaccharides mixture increases the bifidobacterial population numbers in a continuous in vitro fermentation system and in the proximal colonic contents of pigs in vivo. J Nutr 135, 1726-1731.

49. Rodriguez-Cabezas ME, Camuesco D, Arribas B, et al. (2010) The combination of fructooligosaccharides and resistant starch shows prebiotic additive effects in rats. Clin Nutr 29, 832-839.

50. Ben X, Li J, Feng Z, et al. (2008) Low level of galactooligosaccharides in infant formula stimulates growth of intestinal bifidobacteria and lactobacilli. World J Gastroenterol 14, 6564-6568.

51. Bouhnik Y, Raskine L, Simoneau G, et al. (2004) The capacity of nondigestible carbohydrates to stimulate fecal bifidobacteria in healthy humans: a double-blind, randomized, placebo-controlled, parallel-group, dose-response relation study. Am J Clin Nutr 80, 1658-1664.

52. Walton GE, van den Heuvel EG, Kosters MH, et al. (2012) A randomised crossover study investigating the effects of galacto-oligosaccharides on the faecal microbiota in men and women over 50 years of age. Br J Nutr 107, $1466-1475$.

53. Moro G, Minoli I, Mosca M, et al. (2002) Dosage-related bifidogenic effects of galacto- and fructooligosaccharides in formula-fed term infants. J Pediatr Gastroenterol Nutr 34, 291-295.

54. Davis LMG, Martinez I, Walter J, et al. (2010) A dose dependent impact of prebiotic galactooligosaccharides on the intestinal microbiota of healthy adults. Int $J$ Food Microbiol 144, 285-292.

55. Slegte J (2002) Determination of trans-galactooligosaccharides in selected food products by ion-exchange chromatography: collaborative study. J AOAC Int 85, 417-423. 